\title{
Fruit-Based Non-Dairy Beverage: A New Approach for Probiotics
}

\author{
Izabela Alves Gomes ${ }^{1}$, Armando Venâncio² ${ }^{2}$ Janine Passos Lima ${ }^{3}$, Otniel Freitas-Silva ${ }^{3}$ \\ ${ }^{1}$ Graduate Program in Food Science and Nutrition (PPGAN), Federal University of the State of Rio de Janeiro, \\ Rio de Janeiro, Brazil \\ ${ }^{2}$ Centre of Biological Engineering (CEB), University of Minho, Braga, Portugal \\ ${ }^{3}$ Embrapa Agroindústria de Alimentos, Empresa Brasileira de Pesquisa Agropecuária, Av das Américas, Rio de Janeiro, Brazil \\ Email: izabela.nut@gmail.com, avenan@deb.uminho.pt, janine.passos@embrapa.br, otniel.freitas@embrapa.br
}

How to cite this paper: Gomes, I.A., Venâncio, A., Lima, J.P. and Freitas-Silva, O. (2021) Fruit-Based Non-Dairy Beverage: A New Approach for Probiotics. Advances in Biological Chemistry, 11, 302-330. https://doi.org/10.4236/abc.2021.116021

Received: November 8, 2021

Accepted: December 28, 2021

Published: December 31, 2021

Copyright $\odot 2021$ by author(s) and Scientific Research Publishing Inc. This work is licensed under the Creative Commons Attribution International License (CC BY 4.0).

http://creativecommons.org/licenses/by/4.0/

\begin{abstract}
The growing interest of consumers in using foods that improve health has motivated researchers and the food industry to develop new functional products such as foods with probiotics. Probiotic cultures, for example, from lactic acid bacteria and bifidobacteria have been highlighted for their ability to promote balance in the intestinal microbiota as well as other benefits such as anticarcinogenic and antimutagenic effects, reduced plasma cholesterol levels, decreased symptoms of lactose intolerance, and stimulation of the immune response. Traditionally, probiotics are incorporated into dairy products. However, because of the growing number of individuals affected by lactose intolerance and/or vegans, other food matrices have been studied as potential carriers for these microorganisms. Considering all the facts mentioned above, cereals, legumes, fruits, and vegetables could be potential substrates, where probiotic bacteria can be used for the development of non-dairy beverages. This review aimed to highlight the research carried out on 1) probiotic micro-organisms, including the more recent reclassification according to their phylogenetic position, 2) probiotic beverages from non-dairy sources which emerged as an alternative for lactose-intolerant consumers and, 3) the aspects of improving the gut microbiota.
\end{abstract}

\section{Keywords}

Functional Foods, Fruit Juice, Lactobacillus, Non-Dairy Beverages, Gut Microbiota

\section{Introduction}

The term "functional food" seems generic, but the history of the term can be 
highlighted in the late 1960s, for example, with researches that showed that polyunsaturated fatty acids could control the level of cholesterol in the blood [1].

Initially, the concept of functional foods was to seek food with the ability to treat diseases [2]. The concept of functional food emerged in Japan in 1984, with the disclosure of information from the beneficial effects of foods enriched with special components, such as probiotics by Japanese scientists [3]. From 1984 until now, functional food has changed its meaning due to different cultural origins [2]. In 1991, the Japanese Ministry of Health, Welfare, and Labor established "Food for Specified Health Uses" (FOSHU) as a regulatory system for functional foods. FOSHU was the result of a program financed by the Japanese authorities which aim at the reduction of the financial resources spent on public health, containing the progress of chronic diseases. After the introduction of the FOSHU regulation, the number of functional food products increased, especially between 1997 and 2007 [4].

In 2014, at the 17th International Conference on Functional Foods in Health and Diseases, functional foods were granted a new definition as natural or processed foods, containing known or unknown bioactive components in the non-toxic efficacy of performing clinically proven or documented health benefits [3].

In 2015 a new regulatory system for functional foods was established based on the system of the Food Supplement Health and Education Act, already established in the USA. With the introduction of this system, many new functional foods were developed due to the more flexible health claims when compared to FOSHU. This fact provided a growing increase in functional foods, which in 2018 reached an appreciation of around 1.8 billion dollars and this market is still undergoing an exponential and impactful expansion [4].

The European Commission has adopted a definition stating that "a food can be considered "functional" if it is satisfactorily determined to benefit one or more target functions in the body, in addition to having adequate nutritional effects to improve health, health, and well-being and/or reduced risk of disease" [5].

In Brazil, the current legislation on functional foods, approved by the National Health Surveillance Agency (ANVISA) in 1999, does not define the term "functional foods", but rather a functional property claim that is "related to the metabolic or physiological role that the nutrient or non-nutrient has in the growth, development, maintenance and other normal functions of the human organism". As long as ANVISA's General Management of Food and its safety of use evaluate it and its efficacy is proven, the food that bears the claim may be made available on the consumer market [6]. Brazilian legislation prevents the attribution of medicinal and therapeutic effects to foods; therefore, claims cannot be associated with prevention, treatment, or cure of diseases. Specific claims are desirable as they communicate the claimed benefit more clearly to the consumer. This type of allegation should also not be too general, at the risk of not being able to obtain evidence capable of proving the effect and properly communicat- 
ing about the claimed benefit [6].

The fastest-growing sector of functional food worldwide contains probiotics. Probiotic foods consist in represent $60 \%$ to $70 \%$ of the functional food market [7]. In 2015, it was predicted that the food market containing probiotics would increase from $\$ 35$ billion up to $\$ 48$ billion in 2020 [8].

Currently, the demand for functional foods containing bacteria with probiotic properties is growing rapidly due to increased public awareness of the benefits of probiotics for health, maintaining the balance of the intestinal microbiota, and improving mucosal defenses against pathogens [9].

This study aimed to summarize the current state of non-dairy beverages with the addition of probiotics, as well as to demonstrate the potential of the application of probiotics in juices from fruits.

\section{Probiotics}

The intestinal microbiota is a complex ecosystem, which is composed of microorganisms associated with various nutritional, metabolic, endocrine processes, immunological and psychological mechanisms. This complex of microorganisms maintains and regulates some endogenous functions such as nutrient metabolism, immunomodulation, synthesis of bioactive compounds and vitamins, and the fermentation of non-digestible carbohydrates, in short, they serve as a more efficient intestinal selective barrier. Thus, due to the importance of the intestinal microbiome in maintaining health, the search for new probiotics products with single, multi-strain or multi-species strains, associated or not with prebiotics, are sure bets on the market [10].

Romans and Greeks in the past used fermented dairy foods to ensure and maintain health [11]. The definition of probiotics (Greek; Pro: promotion, biotic: life) as living microorganisms, which when administered in adequate quantities, can offer a benefit to the health of the host, was established by the United Nations Food and Agriculture Organization (FAO) and by World Health Organization (WHO) in 2001 [12].

In Brazil, the National Health Surveillance Agency (ANVISA) defines probiotics as live microorganisms which are capable of improving the intestinal microbial balance, producing beneficial effects on the health of the individual when administered in adequate doses [13] [14].

Probiotics are defined by The World Gastroenterology Organization as live microorganisms that, when administered in quantity, confer health benefits on the host. The species of Lactobacillus and Bifidobacterium are the most used as probiotics, but the yeast Saccharomyces boulardii and some species of E. coli and Bacillus are also used. The new agents also include Clostridium butyricum, recently approved as a novel food in the European Union. Government regulations differ between countries, however, the status of probiotics as a component in foods is not currently established on an international basis. For most countries, probiotics come in dietary and dietary supplements because most come in the form of foods [15]. 
Probiotics also called living biotherapeutic products (LBP), are products that contain living organisms, such as bacteria, found naturally in humans. Government regulation of probiotics in the United States is complex. Depending on the intended use of a probiotic product, the Food and Drug Administration (FDA) may regulate it as a dietary supplement, food ingredient, or drug [16].

The mechanisms of action of probiotics are not always well understood, which are one of the problems considered by the European Food Safety Authority (EFSA), which in 2014 rejected the health claims of marketed probiotics due to lack of sufficient evidence [17].

Historically, the concept of probiotics was developed around 1908 by the Nobel Prize winner Elie Metchnikoff, who discovered that the consumption of live bacteria (Lactobacillus bulgaricus) in yogurt or fermented milk could improve some biological characteristics of the gastrointestinal tract [7] [12]. In his study, Dr. Metchnikoff concluded that a bacterium helps control the effects caused by enteric pathogens and toxemia, which play an important role in aging and mortality. This research resulted in an increase in the production and consumption of yogurt all over the world [11].

In 1965, Lilly and Stillwell used the term probiotic for the first time. Over the next decade, the term was used by Fujii and Cook in 1973 and denoted chemicals in mice that protected against Staphylococcus aureus infection. In 1974, the term was used by Parker in a broader sense to refer to interactions of microorganisms with the animal or human host, that is, "organisms and substances which contribute to balance microbial proliferation". Finally, in 2013, the consultation of experts from international scientists at the meeting of the International Scientific Association of Probiotics and Prebiotics provided minor grammatical corrections and reformulated the previous definition as "living microorganisms that, when administered in adequate quantities, confer a benefit to the health of the host", which is now widely accepted and used. Several studies on probiotics have been published since this discovery [11].

The daily recommendation for ready-to-eat probiotics must contain at least a minimum amount of viable cells in the range of $10^{8}$ to $10^{9}$ colony forming units (CFU). Smaller values are acceptable, as long as its effectiveness is proven [18]. The viability of probiotics should be ensured during processing and storage, aiming to keep their counts at high levels $\left(10^{6}-10^{7} \mathrm{CFU} / \mathrm{mL}\right.$ or $\mathrm{g}$ of food) until consumption [19].

The World Gastroenterology Organization considers that a required dose of probiotics varies greatly depending on the strain and the product. Although many products provide between $1-10$ billion CFU/dose, some products are effective at lower levels, while others are at higher amounts. It is not possible to establish a general dose for probiotics; since the dosage has to be based on human studies that show a health benefit [15].

In Brazil, the ANVISA legislation on foods with alleged functional and/or health properties, new foods/ingredients, bioactive substances, and probiotics has such probiotic microorganisms approved for use in food: Lactobacillus acido- 
philus, Lacticaseibacillus casei shirota; Lacticaseibacillus casei variety rhamnosus; Lacticaseibacillus casei variety defensis; Lacticaseibacillus paracasei; Lactococcus lactis, Bifidobacterium bifidum; Bifidobacterium animallis (including the subspecies B. lactis); Bifidobacterium longum; Enterococcus faecium [20].

All probiotic species are considered safe for the general population by the European Food Safety Authority (EFSA). The U.S. Food and Drug Administration (FDA) classifies probiotics individually but also classifies them as safe for food use [10]. For a single strain to reach probiotic status, it is necessary to assess its resistance to the digestion process and its ability to promote health benefits [10].

Probiotics have been used in food with the main objective of strengthening the natural intestinal microbiota. Its effectiveness in improving health status depends mainly on its ability to provide viable functional bacteria, overcoming the harsh effects of the intestinal tract [6]. Raising their health benefits, probiotic bacteria with activity have been increasingly added to a range of products, including yogurts, cheeses, ice cream, powdered milk, and frozen desserts [6]. Viable microorganisms such as lactobacilli and bifidobacteria that benefit the host by improving intestinal bacterial balance are the most used by the industry, as they have several typical characteristics such as metabolic stability, adherence to intestinal cell walls, without promoting antibiotic resistance and not pathogenic, safe for the consumption and effective. Besides that, these bacteria must be active in the product, survive throughout the upper digestive tract, resist gastric juice, oxygen, and enzymes, and can co-aggregate as a part of the natural intestinal microbiota and have beneficial effects after adhering to the host's intestine [21] [22].

The world market for probiotics including their use as an ingredient, supplements, and their incorporation in food products is increasingly expanding [11] and according to Transparency Market Research was estimated to reach U\$12,753 million by 2026 .

Preclinical and clinical studies on the benefits of probiotics to gastrointestinal health has shown effects on 1) prevention of acute diarrhea associated or not with antibiotics, 2) symptomatic relief in irritable bowel syndrome, 3) treatment of hepatic encephalopathy, and 4) prevention of necrotizing enterocolitis in premature babies [23]. Probiotics act as antagonists to pathogens such as Enterococcus faecalis, Salmonella enterica subsp. enteric serotype Enteritidis, Listeria monocytogenes, E. coli and Staphylococcus aureus by immunological, hormonal and neuronal manipulation [24]. Specific probiotics also have gained a place in the treatment of ulcerative colitis and are useful to combat overweight, obesity and are recommended as options in the main clinical guidelines [25].

To avoid miscommunication about all living species, biological knowledge on taxonomy and nomenclature should be considered when choosing probiotics. [26]. In the strictest sense, taxonomy deals with the theory and classification practice, including principles, rules, and methods. When new species or higher taxa are discovered or in case of revised or reclassified taxon, taxonomists publish a formal description of each change to establish names and circumscribe the 
corresponding taxonomic concepts or to amend existing ones to reflect their discoveries [27].

When DNA-DNA hybridization method, used since 1960 for bacterial taxonomy, suffers from reproducibility problems and cannot provide an accurate measurement of the actual sequence identity between genomes [28], new strategies need to be found. For exemple the genus Lactobacillus was proposed by Beijerinck in 1901 and includes Gram-positive microorganisms, fermentative, optionally anaerobic, and non-spore-forming, which can also be mobile, catalase-negative when cultivated without heme on the medium, usually oxygen tolerant, aciduric or acidophilic, mandatorily saccharolytic with at least $50 \%$ of the final carbohydrate product being lactate and other fermentation products consisting of acetate, ethanol, $\mathrm{CO}_{2}$ and succinate. Several types of fermentation can be recognized, such as metabolisms that are mandatory homofermentative, optionally heterofermentative, and mandatorily heterofermentative, based on the types of fermented sugars (hexoses and pentoses) and fermentation products [29]. The genus is classified in the phylum Firmicutes, class Bacilli, order Lactobacilalles, family Lactobacillaceae, which contains the genera Lactobacillus, Paralactobacillus, and Pediococcus [30]. The Lactobacillaceae family contains the genera Lactobacillus and Pediococcus, which are phylogenetically mixed. The ancient genus Paralactobacillus was recently included in the genus Lactobacillus, although this inclusion is questionable. More than 150 species are recognized in the genus Lactobacillus and are heterogeneous in several properties [29].

In the past two decades, sequencing of entire bacterial genomes has become widely available and the mean values of the nucleotide identity (INA) of the genes shared between different bacterial genomes has been introduced as the "gold standard" for the design of new bacterial species [30]. Due to the relatively small size of the bacterial genome and the greater availability of high-throughput sequencing DNA technology, phenotypic testing has now been replaced by genome sequencing as the main source of taxonomic information [26].

Since 1983, the similarity between the 16S rRNA genes has been used in bacterial taxonomy to provide phylogenetic schemes as a backbone for classification and nomenclature. Limitations to the 16S rRNA gene approach; for example, many recently divergent species that have undergone intense evolutionary pressures may have highly similar $16 \mathrm{~S}$ rRNA gene sequences that can, however, ignore a wide phylogenetic gap between such taxa [28]. Based on parameters as the Average Aminoacid Identity (AAI) and the Percentage of Conserved Proteins (PCPO), this genus has a wide range that far exceeds the normal spread of a genus [26]. From the available genome sequences, 16 groups were discriminated within the Lactobacillus genus. Forteen (14) stable phylogenetic groups were described within the genus, based only on $16 \mathrm{~S}$ rRNA sequence similarity. According to the taxonomic subcommittee on Bifidobacterium, Lactobacillus and related organisms this taxonomic aspect was discussed and they decided for a formal division of the genus, creating a working group to collect all available genotypic and phenotypic information that would allow defining a new, reliable and 
stable structure for the genus Lactobacillus [26].

In the First International Taxonomy Congress, held in 1930 in Paris, France, the first "Bacterial Code" was developed. This code updates qualitatively the bacterial nomenclature, reducing the duplicate names and including a better description of the different species and corresponding Type strains [26]. The Procaryotes International Nomenclature Code defines rules for the nomination of bacterial taxa based on their taxonomic classification. Although it covers many exceptions and particular cases, its principles are relatively simple; but, as the Code stands, it is not easy to find reasons for name changes of the genus Lactobacillus [26]. In the Lactobacillus genus the species were included based on several common phenotypic characteristics. For a reclassification of the genus, the demonstrated genetic distinctions within the genus should be supported by a discriminative set of parameters which, in addition to genome sequence, will allow a reliable and consistent description of a new genus. So, it is necessary to collect available information on all known Lactobacillus species, exploring different bioinformatic tools, and eventually arrive to a possible reclassification for the genus [26].

By March 2020, 261 species of Lactobacillus had already been described. The genus Lactobacillus is very heterogeneous and in the last decades, more than 250 species have been attributed to this genus [30].

The previous taxonomy of lactobacilli was based on phenotypic factors and characteristics such as the ideal temperature of growth, use of sugar, and range of metabolites produced [30]. Later in the 20th century, genotypic and chemotaxonomic criteria (e.g., chemical structure of peptidoglycans) were used to design new bacterial species [30].

A new perspective for taxonomy, the Total Nucleotide Identity (TNI) was found between the expected values between order and family and the INA values between Order and Class for the 237 species of Lactobacillus (208, excluding synonyms and subspecies). In the same study, Pot et al. [26] showed that representatives of the Pediococcus genus, and members of Leuconostocaceae family are mixed with species within the Lactobacillus genus. But the genus continues to grow, and new isolates are continuously being added, which the latter authors find scientifically unacceptable. rRNA gene sequence analysis introduced a tool for a more exhaustive and robust taxonomy for the genus with the introduction of $16 \mathrm{~S}$, but ended by revealing fewer correlations between traditional classification based on phenotype and the new phylogenetic one. The continuous description of new species of Lactobacillus, led to the recognition of an increasing number of variable phylogenetic subgroups [26].

Zheng et al. [30] states that it is recognized according to the level of genetic diversity found for the Lactobacillus genus exceeds what is commonly found for other bacterial genera and even for bacterial families. The availability of complete genomes of Lactobacillus strains, representing the main families of the Lactobacillales order, has allowed a more definitive analysis of their evolutionary relationships [29]. 
Recommendation 30b of the Bacteriological Code of Nomenclature (1990 Review), as modified at the 1999 meeting of the International Committee for Systematic Bacteriology (ICSB) and its Judicial Commission, calls for the definition of minimum standards to describe new bacterial taxa [29].

With the description of the new genus, the researchers suggested keeping the initial "L" for the new genus names to minimize confusion. This way, considered commercially important species such as Lacticaseibacillus casei, Lactiplantibacillus plantarum, and Limosilactobacillus reuteri, which will no longer be lactobacilli and will be included in a new genus, will be abbreviated as $L$. casei, $L$. plantarum, and L. reuteri. Other commercially important species of Lactobacillus, including species and strains with fermentation capacity and others with proven probiotic activity, will be mainly found in the newly defined genera. In this way, the number of species of the genus Bifidobacterium, Lactobacillus, and related genera has increased considerably over the past 10 - 15 years [29].

Thus, some guidelines have been defined to recommend the labeling of probiotics using a current nomenclature for genera and species, although there is a greater concern from a practical and financial standpoint, there is a clear demand for stability in the new classification system [26].

\subsection{Probiotic Products Availability on the Market}

After in vitro and pre-clinical research, or after large-scale clinical trials, a substantial number of microbial species have been revealed to exhibit potential probiotic properties, however, only the most documented and robust strains can reach the market [31]. Most of the current probiotics are lactic acid bacteria (LAB), which belong to the genus Lactobacillus and Bifidobacterium, with a smaller number of leuconostocs, pediococci, lactococci, enterococci, and streptococci. A variety of species of LAB are listed as generally recognized as safe (GRAS) and comprise the probiotic species that are the most used in supplements or food matrices. The most commonly used probiotics are species of $B i$ fidobacterium (B. animalis, B. bifidum, B. breve, B. infantil, B. longum, B. lactis), and species of Lactobacillus (L. acidophillus), Lacticaseibacillus (L. casei, L. rhamnosus), Lactiplantibacillus (L. plantarum), Ligilactobacillus (L. salivarius) and Limosilactobacillus (L. fermentum, L. reuteri). Other species as Streptococcus and Bacillus or the yeast Saccharomyces cerevisiae are also used as probiotics, and incorporated in non-dairy foods. There has recently been a reclassification of Lacticaseibacillus, Lactiplantibacillus, Ligilactobacillus, and the genus Limosilactobacillus, which previously comprised the genus Lactobacillus. Although the use of some Bacillus or Clostridium spp. may seem to be controversial from a security perspective, the technological advantage for using spores compared to the most vulnerable plant cells explains the increased interest in research and commercial development for these species [31] [32].

A beneficial effect on the host is obtained if a minimal amount of viable probiotic cells reaches the intestine. The suggested minimum amount in food at the time of consumption is around $10^{8}$ viable cells per $\mathrm{mL}$ or $\mathrm{g}$ of food, so that the 
observed survival during exposure in the gastrointestinal tract (GIT) cannot compromise the functionality of probiotics. Despite the differences between the daily amounts recommended by American or European agencies for making health claims, it was proposed that the daily intake should be from 6 to $9 \log$ $\mathrm{CFU}$ probiotic $\mathrm{g}^{-1}$ or $\mathrm{mL}^{-1}$ for its effectiveness. However, to claim specific health effects, the required dose may be lower and it is specific to each strain [32].

Dairy industries and LAB preparation companies in Europe, Japan, and the United States have developed their own internationally renowned strain brands, as well as product brands. And, to assess the probiotic functions, these strains have been submitted to many clinical trials. Bifidobacterium lactis BB-12 strain, developed by Chr. Hansen (Denmark), is reported as the most studied Bifidobacterium strain in the world. Over the past 80 years, the strain Lacticaseibacillus casei Shirota from Yakult Company has undergone a large number of scientific studies and clinical trials. In late May 2015, its survival, efficacy, and safety in the gut were scientifically verified in China, Japan, Thailand, UK, and elsewhere [33].

Large differences are observed between strains from the same species, as they may have different phenotypes and properties that can lead to different clinical effects [31].

Many studies have found out that the addition of probiotic cultures in foods has not influenced the sensory acceptance of the products [32].

\subsection{Dysbiosis}

Dysbiosis, an imbalance in the intestinal microbiota composition after the use of antibiotics, has largely boosted the therapeutic application of probiotics [24]. A consideration of the intestinal microbiota is necessary to understand its relevance to human health and the concept of probiotic food. Each individual has in its gastrointestinal tract a unique signature with more than 1000 microbial species. The bacterial cells comprehend half the wet weight of the colon material and its number reaches 10 times over the number of cells in the tissue that forms the human body.

Normally, the stomach contains $10^{3}$ different bacterial species, while the total microbial population of colon bacteria is around $10^{11}$ and $10^{12} \mathrm{CFU} / \mathrm{g}$. The bacterial colonization of the intestine begins at birth when newborns are exposed for the first time to a non-sterile environment. Thereafter, it evolves and transforms throughout life, depending on a complex and dynamic interaction between the host diet, genome, and lifestyle, as well as the use of antibiotics. The composition of the intestinal microbiota is generally considered to be essentially stable throughout adulthood [25].

The vast majority of clinical trials of probiotics reported in the literature have not given rise to major concerns. However, some examples of serious adverse effects of probiotics have been documented regardless of formulation, dosage, and daily consumption [12].

Lactobacillus and Bifidobacterium are common genera of the endogenous mam- 
malian gastrointestinal tract. They induce host immunomodulation and reduce symptoms of a wide range of gastrointestinal disorders, and therefore have been widely used as probiotics. The cell membrane integrity, the intracellular $\mathrm{pH}$, and the functional enzymes of probiotic cells can be constantly attacked by stress factors such as bile acids, digestive enzymes and gastric acidity during their passage through the gastrointestinal tract. As a consequence, probiotic cells can be viable (active and cultivable), inactive (inactive, but cultivable), active (but not cultivable), or dead (inactive and non-cultivable). Cells that experience a high level of stress may still have some metabolic activity, but they may no longer be cultivable [10].

Even inactive probiotic cultures or their fragments are also being investigated by researchers and have been shown to have effects such as an improvement in adverse behaviors (mental health) related to sleep disorders, stress, regulation of intestinal function, and positive effects on the administration of immunity and allergy. These non-viable cells also present advantages for the food industry, making products safer and more stable. These types of applications deserve special attention for patients in critical states for whom the risks of consuming active cultures are quite high [10].

\subsection{Mechanism of Action and Probiotic Activity}

Probiotics create a favorable environment for the intestine, through their mechanisms of action, which will depend on a variety of factors, such as the type of strain used, the host, and the food. The probiotics can improve the epithelial barrier promoting mucus secretion. Furthermore, some probiotic strains release active peptides, also known as bacteriocins, against bacteria, fungi, and viruses, which may stabilize the intestinal barrier. Other antimicrobial substances are also produced by probiotics, such as lactic and acetic acid, that present an inhibitory effect on Gram-negative bacteria [6].

In this way, the probiotics act in several ways, interfering with the adhesion of pathogens to the intestinal mucosa [6]. As there are different strains and product formulations, there is not a single answer. An intriguing aspect of probiotic strains is the ability of some to confer distant effects at the site of administration. This can occur through the transfer of organisms, for example, from the intestine to the mammary glands of breastfeeding women [34].

The mechanisms by which probiotics exert their effects, in general, are largely unknown, but they may involve changing the intestinal $\mathrm{pH}$, antagonizing pathogens through the production of antimicrobial compounds, competition for binding sites and pathogen receptors, as well as nutrients and factors of available growth, stimulation of immunomodulatory cells and lactase production [23]. As described in Figure 1, there may be four different mechanisms in which probiotics can defend the body against pathogens.

Bacteria with probiotic properties are now widely available in the form of foods, such as dairy products and juices, as well as capsules, drops, and powders [12] [25]. 
(a)

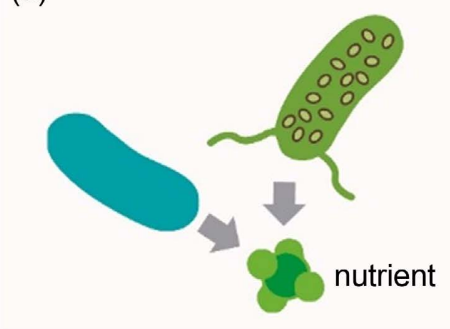

(c)

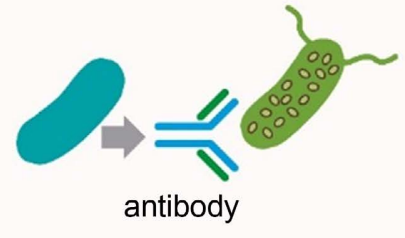

(b)

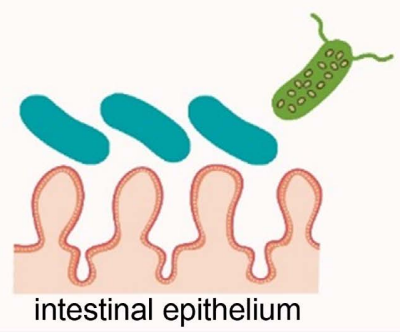

(d)

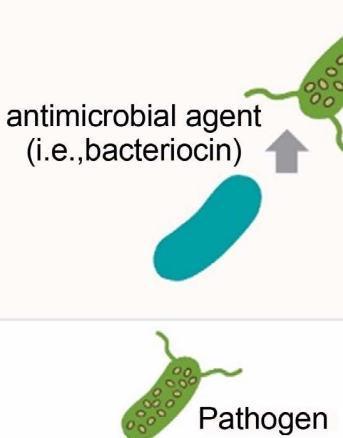

Figure 1. Probiotics functions against the pathogen in the intestine by: (a) competing against pathogens for the same essential nutrients, thus making it less available for the pathogen to use, competition for nutrients; (b) attachment to the adhesion sites and, therefore, preventing attachment of the pathogen by reducing the surface area available for colonization of the pathogen, Blocking of adhesion sites; (c) sends a signal to the immune cells that result in the secretion of cytokines, which target the pathogen for destruction, Immune stimulation; (d) attacking pathogenic organisms by releasing antimicrobial agents, such as bacteriocins, that kill them directly (adapted from Fazilah et al., 2018), direct antagonism.

Traditionally, a wide range of fermented foods such as yogurt, kefir, kimchi, sauer-kraut, tempeh, miso, and kombucha are part of the regular diet in different cultures and ethnicities, ranging from eastern to western, serving as a conventional source of probiotic strains [24].

Studies have shown that the specific food matrix can affect probiotics, by allowing their multiplication and protecting the product's shelf life, as well as providing protection in the passage through the gastrointestinal tract. Foods with high $\mathrm{pH}$ or high buffer capacity can reduce stomach acidity in humans, promoting the survival of probiotic micro-organisms. In addition, liquid foods are digested more quickly than solid foods, consequently reducing the exposure of probiotics to agents of stress, such as stomach acid [35]. Probiotics demonstrate the beneficial effects as shown in Table 1.

Dairy beverages have been the most popular source of probiotics. However, due to the market demand for plant-based beverages (e.g., vegetarianism and veganism) and to consumer awareness of adverse reactions to dairy products (intolerance and malabsorption) functional non-dairy beverages became an alternative carrier for probiotics [43]. It is weell knowm the association for the intake of dairy products with lactose and milk protein intolerance. Besides that, 
Table 1. Probiotic functions.

\begin{tabular}{|c|c|c|}
\hline Strain & Action & Reference \\
\hline Lactobacillus & $\begin{array}{l}\text { Significant decrease in gastrointestinal } \\
\text { symptoms, including nausea, postprandial } \\
\text { fullness, and gastrointestinal pain }\end{array}$ & {$[36]$} \\
\hline Lactobacillus & Decreased inflammation related to $H$. Pylori & {$[36]$} \\
\hline Lactobacillus & $\begin{array}{l}\text { Relief of symptoms of lactose intolerance, } \\
\text { cholesterol reduction }\end{array}$ & [37] \\
\hline $\begin{array}{l}\text { Sacharomyces } \\
\text { boulardii }\end{array}$ & Anti-inflammatory activity & [38] \\
\hline $\begin{array}{l}\text { Saccharomyces } \\
\text { boulardii }\end{array}$ & $\begin{array}{c}\text { Recommended for the treatment of acute } \\
\text { gastrointestinal diseases, such as rotaviral } \\
\text { and bacterial diarrhea and chronic conditions, } \\
\text { such as inflammatory bowel disease }\end{array}$ & [39] \\
\hline $\begin{array}{l}\text { Lactobacillus } \\
\text { acidophilus }\end{array}$ & $\begin{array}{l}\text { Changes in the profile of inflammatory cytokine } \\
\text { production and regulation of proinflammatory } \\
\text { pathways, inhibition of the adhesion of } \\
\text { pathogenic bacteria, modification of the } \\
\text { microbiota by acidification of the colon } \\
\text { due to fermenting agents, improvement } \\
\text { in the function of the epithelial barrier, } \\
\text { and protection against physiological stress }\end{array}$ & {$[40]$} \\
\hline $\begin{array}{l}\text { Bifidobacterium } \\
\text { longum }\end{array}$ & Associated with carbohydrate metabolism & {$[41]$} \\
\hline $\begin{array}{l}\text { Bifidobacterium } \\
\text { longum }\end{array}$ & $\begin{array}{l}\text { Protection against autoimmune diseases } \\
\text { such as inflammatory bowel disease, } \\
\text { metabolic syndromes, irritable bowel } \\
\text { syndrome colitis and brain disorders }\end{array}$ & {$[41]$} \\
\hline $\begin{array}{l}\text { Lacticaseibacillus } \\
\text { rhamnosus }\end{array}$ & $\begin{array}{l}\text { Beneficial for vaginal and } \\
\text { postpartum female health }\end{array}$ & {$[42]$} \\
\hline $\begin{array}{l}\text { Lactobacillus } \\
\text { acidophilus }\end{array}$ & Decrease in toxins produced by the kidneys & [43] \\
\hline
\end{tabular}

the higher saturated fat and cholesterol content in dairy based products compared to plant-based ones is also an inhibiting factor among some health-conscious consumers. The aforementioned concerns have opened a path for probiotic non-dairy products. The flavor and refreshing nature are the main advantages of non-dairy probiotics, as they include fermented products from cereals, soy, meat, fruits, and vegetables, enriched with various nutrients, vitamins, and antioxidants [44].

\subsection{Clinical Effect of the Consumption of Probiotics}

The World Health Organization stated that up to 38 million people died from chronic diseases worldwide in 2012, of which more than $40 \%$ died of premature death, and this value was much higher than in 2000 (14.6 million). Inadequate 
dietary fiber intake is another major cause of chronic diseases, which can lead to the loss of some intestinal microorganisms, which can later result in various chronic diseases [33]. The growing number of studies shows the association between intestinal microbiota and chronic diseases that helped to develop the hypothesis that modulation of the intestinal microbiota may be a factor that links the environment with the genetics and diseases of the host [45] [46].

The intestine is one of the organs most important organs in the human body. It contains more than $70 \%$ of the body's mucosal immunity. In addition, the intestine is closely related to various parts of the body through complex immune mechanisms. Therefore, considerable attention must be paid to intestinal health to achieve a healthy lifestyle [33].

More than 300 scientific publications describe the benefits of using probiotics, of which more than 130 are related to clinical studies in humans [33]. One study demonstrated that tomato and bean juices fermented with Lactiplantibacillus plantarum LP DSM20205 (formerly known as Lactobacillus plantarum LP DSM20205) could have an important effect on the integrity and adherence of the barrier, being the most pronounced effect for fermented tomato juice. Probiotic cultures isolated from plant products could also have in vitro effects. For instance, Lactic acid bacteria (LAB) isolated from fermented cocoa juice and their metabolites have demonstrated antagonistic activity against Helicobacter pylori, which is associated with gastric ulcers. Also, Pediococcus pentosaceus SC28 and Levilactobacillus brevis KU15151 (formerly known as Lactobacillus brevis KU15151) from traditional Korean food (jeotgal octopus and kimchi radish) showed adherence rates of $4.45 \%$ and $6.30 \%$, respectively, to HT-29 cells, which is a human colon adenocarcinoma cell [32].

Vegetable products with the addition of vegan probiotics could have hypocholesterolemia in vitro and anticarcinogenic effects. The addition of Lactiplantibacillus plantarum-1 (formerly known as Lactobacillus plantarum-1) and Lacticaseibacillus rhamnosus GG (formerly known as Lactobacillus rhamnosus GG) on the blueberry bagasse presented potential benefits on the cholesterol reduction this fact is to the hydrophobic bonding, increasing the excretion of cholesterol [32] [47].

Immunomodulatory and control of diabetes properties have also been associated with plant products added with probiotics. Lychee juice fermented with Lacticaseibacillus casei FL (formerly Lactobacillus casei (FL) was used to investigate the effects on immunity and intestinal microbiota in mice. Also, consumption of soy milk containing Lactiplantibacillus plantarum A7 (formerly Lactobacillus plantarum A7) resulted in antioxidant properties and decreased the risk of incompatible base pairs in DNA among patients with type II diabetes [32].

\section{Non-Dairy Products with the Addition of Probiotics}

Probiotic cultures are usually added to dairy products; besides that, consumers 
are used to the presence of microorganisms in this type of product [15]. However, lactose intolerance, veganism, high cholesterol content, and allergy to milk proteins are limiting factors in the growth of dairy products with probiotics. In total, $75 \%$ of the world's population suffers from lactose intolerance [48]. According to previous studies, higher milk fat content has shown inhibitory effects for probiotic cultures, particularly B. bifidum in yogurt [49].

The use of probiotics in non-dairy products has increased, probably, due to the growing number of adherents to veganism, thus opening room for demand for products free of ingredients from animals [50]. Therefore, other food matrices are being evaluated as carriers of bio-culture, aiming to provide other options to the market, especially to consumers who do not appreciate or cannot consume milk products, including people who are lactose intolerant, allergic to proteins milk or strict vegetarian (vegan) [13].

Probiotic beverages can be made from various raw materials, such as vegetables, corn, legumes, and fruits [51] [52].

Juices (from fruits) can represent an alternative means for adding probiotic cultures because they are considered healthy products and are regularly consumed. In addition, fruit juices are rich in sugars, minerals, and vitamins, which are used as a substrate by probiotics and in combination with a rapid passage through acidic stomach conditions result in the high viability of probiotic cells [13] [37] [52].

Unlike dairy products, fruits and vegetables do not have allergens, lactose, and cholesterol, which adversely affect certain population groups [37]. They are healthy, refreshing, have a good taste, and may be suitable for probiotics. Because they are considered perishable products, fruits require immediate processing to reduce post-harvest losses and the development of probiotic products can be an approach to increase the product's availability and market value. Fruit-based probiotic products are made from pineapple, blackberry, apple, strawberry, lemon, mango, grape, cashew, oranges, carrot, beet, etc., as shown in Table 2 [48].

A variety of types of probiotic fruits and vegetables have been developed and marketed including fruit and vegetable juices, dried fruits, fermented vegetables, and desserts for vegetarians. However, studies that show the feasibility of incorporating probiotic bacteria in fruits and vegetables, and found that their feasibility and stability in these foods are highly dependent on several factors [37]. Fruits, such as apples, guava, bananas, and melons, are potential carriers of probiotic bacteria and strong adhesion of these bacteria to fruit tissue [64].

Considering that fruit and vegetable beverages are an excellent source of vitamins, antioxidants, minerals, and bioactive compounds and represent a good alternative to dairy matrices and a good choice. Different fruits and vegetable juices in the fermentation process can increase the nutritional and functional properties, with beneficial effects on health, in addition to increasing the shelf life of beverages [19]. 
Table 2. Probiotic fruit drinks.

\begin{tabular}{|c|c|c|c|}
\hline Strain & Fruit & Shelf life & Reference \\
\hline Saccharomyces cerevisiae & Cherry & 21 days & [43] \\
\hline $\begin{array}{l}\text { Bifidobacterium animalis subsp. } \\
\text { lactis and Lactobacillus acidophilus }\end{array}$ & $\begin{array}{l}\text { The mix of banana, } \\
\text { strawberry, and } \\
\text { juçara beverage }\end{array}$ & 90 days & {$[52]$} \\
\hline Lactiplantibacillus plantarum & Apple & 3 days & {$[53]$} \\
\hline $\begin{array}{l}\text { Lactiplantibacillus plantarum } \\
\text { Bifidobacterium breve and } \\
\text { Streptococcus thermophilus }\end{array}$ & $\begin{array}{l}\text { The mix of orange, } \\
\text { carrot, apple }\end{array}$ & 21 days & {$[54]$} \\
\hline $\begin{array}{c}\text { Lactiplantibacillus plantarum, } \\
\text { Lactobacillus delbrueckii }\end{array}$ & Cabbage juice & - & {$[55]$} \\
\hline $\begin{array}{c}\text { Lactobacillus spp., } \\
\text { Leuconostoc mesenteroides, } \\
\text { Bifidobacterium longum }\end{array}$ & $\begin{array}{l}\text { Carrot and } \\
\text { orange juice }\end{array}$ & - & {$[56]$} \\
\hline $\begin{array}{l}\text { Lactiplantibacillus plantarum, } \\
\text { Lacticaseibacillus casei, } \\
\text { Lacticaseibacillus paracasei, } \\
\text { Lacticaseibacillus rhamnosus }\end{array}$ & Cherry & 12 days & [57] \\
\hline Lactiplantibacillus plantarum & Cornelian cherry & 28 days & {$[58]$} \\
\hline Lacticaseibacillus casei & Pineapple & 42 days & {$[59]$} \\
\hline Lacticaseibacillus casei & Apple & 42 days & {$[60]$} \\
\hline Lacticaseibacillus casei & Lychee & 28 days & {$[30]$} \\
\hline $\begin{array}{c}\text { Lactiplantibacillus plantarume } \\
\text { Lactobacillus. delbrueckii }\end{array}$ & Pomegranate & 28 days & {$[61]$} \\
\hline $\begin{array}{c}\text { Lactiplantibacillus plantarum e } \\
\text { Lactobacillus acidophilus }\end{array}$ & Orange & 3 days & {$[62]$} \\
\hline Lactobacillus e Bifidobacterium & $\begin{array}{l}\text { Orange, pineapple, } \\
\text { and cranberry }\end{array}$ & 84 days & {$[63]$} \\
\hline
\end{tabular}

Researches with non-dairy symbiotic beverages fermented beverages, including different types or mixed vegetables or fruits, with different concentrations of inulin, pomegranate juices, and cherry beverages using wheat bran, apple juice with oligofructose, orange juice with oligofructose, orange juice and hibiscus tea mixed with oligofructose and berry (strawberry, blackberry, and papaya) supplemented with three separate prebiotics: FOS, inulin, and galactooligossaccharides has been a constant search [13] [19]. In some cases, LABs can bio-transform polyphenols into phenolic compounds with better bioavailability and bioactivity during the fermentation time [65].

However, adding probiotics to fruit juices is more complex when compared to adding to the dairy matrix. The main challenges faced this, are due to some intrinsic properties of these products, such as low $\mathrm{pH}$ and high concentration of organic acids, associated with other important factors like storage time and con- 
ditions for maintaining the viability of probiotics. In addition, fruit juices are considered highly perishable products and contain a large amount of water, which leads to a higher cost of transportation and production [53]. The disadvantage of non-dairy beverages is some unpleasant flavors caused by probiotics are almost perceived by the consumer [49].

Patents involve an admirable transfer of knowledge, both in terms of dispersing information about the deposits, and through the diversified use of scientific and technological knowledge necessary to produce the patented technology [66]. Patent-based statistics assume the innovative performance of a country, company, or institution, as well as other aspects that involve the innovation process. There was an effective start of patent filings from the year 2000, this fact may be related to the growth due to the increasing demand for functional foods since they are important for nutrition that helps in improving health and quality of life. Dairy beverages grew by $2.5 \%$ between 2008 and 2011 [66].

Currently in Brazil, the panorama regarding the protection of new products characterized as probiotics, focusing on non-dairy food matrices indicates that the products already patented on this topic fall on the production of non-alcoholic beverages fermented with probiotics, mainly of the genus Lactobacillus and/or Bifidobacterium, with fruits as a food matrix, and a patent on a smoothie, using the same genera of microorganisms and food matrix as the others [67]. It is necessary to encourage mainly in Brazil, the development of technological innovations aimed at patenting of the methods, the preparation of probiotic products, given that these are influencing the quality of life and preventing diseases that affect the world population [68].

Spray drying is the most used technique in the production of juice powders. In addition, it is widely used for microencapsulation of bioactive components, including probiotics, providing protection against adverse environmental conditions and improving processing and stability during storage [52]. In addition to being a quick-drying process, this technique has other advantages, such as relatively low cost, simplicity of use, and continuous operation capability. Although in some cases high temperatures used on processing and the low moisture content can lead to the decreased survival of the probiotic cells, to overcome these limitations polysaccharides especially those with prebiotic properties, such as inulin and oligofructose, can be used for the microencapsulation of probiotics increasing the viability of probiotic cultures [52] [66].

During the processing and storage of the products, oligofructose is the available substrate for the metabolism of these microorganisms and, thus, could increase the stability of probiotics in fruit juices during storage. In addition, oligofructose can be used as a sugar substitute, as it has a sweet taste similar to sucrose [13].

\subsection{The Market of Vegetable Beverages with Probiotics}

Combining probiotics with fruits and vegetables can be interesting as it provides the probiotics and dietary fiber the body needs, indicating an important direc- 
tion of development for the probiotic industry in the future [48]. The combination of "probiotics + fruits and vegetables" takes many forms; of these, the direct addition of probiotics to existing traditional fruits and vegetables is the simplest way and the best approach is to ferment raw fruits and vegetables using probiotics strains [33].

The probiotic industry is expanding rapidly and new probiotic products are constantly been developed. The global probiotics market is estimated to be worth $\$ 15$ billion a year and is growing at an estimated 7\% annual rate [45]. This increase has led to a large number of new products including probiotics on supermarket shelves as well as in drugstores [31].

In recent years, there was an increase in vegetarianism and veganism and with that, the consumer demand for products with high nutritional value has increased too. People are increasingly avoiding products derived from animals (i.e., vegetarians and/or vegans) and this has become a growing trend in modern lifestyles. In addition to that, many consumers started to demand plant-based milk alternatives for sustainability, health, dietary, and lifestyle issues or broader social or political reasons, resulting in an abundance of fruits, seeds, nut products or beans. Also, the global market for alternatives to non-dairy beverages has become a multi-billion-dollar business and will account for approximately U $\$ 26$ billion in 2023 [32] [34].

In this scenario, the development of new products that are nutritionally balanced and/or add value stands out for their practical use as probiotics should be emphasized because of its proven effectiveness and wholesomeness, and the adaptability of probiotic cultures in different food matrices. Teas, fruit juices, or fermented drinks are matrices composed of bioactive compounds, such as vitamins, minerals, and polyphenols, representing interesting matrices for the addition of probiotics. However, there is always a need to assess the survival of the probiotic culture and its impact on the quality characteristics of the product [32].

It is necessary to exhaustively select excellent strains for the fermentation of different fruits and vegetables, as LAB derived from plants such as $L$. plantarum and $L$. acidophilus have gradually come to be used for the fermentation of fruit and vegetable juices. There is also a lack of high-density cultivation technology for fruit and vegetable fermentation varieties suitable for industrial production that needs to be incremented [34]. The industry still faces several important scientific and technological issues. More strains with excellent fermentation performance are needed to develop and the effects of prebiotics, probiotics, and fermented fruit and vegetables on human health, in addition to their mechanisms of action, should be better understood. Research and industries in the field of fruits and vegetables fermented with probiotics will have greater development opportunities if these problems can be effectively addressed [34].

\subsection{Study for the Viability of Probiotics}

In the development of functional foods with probiotic microorganisms, the for- 
mulation, processing, and storage should favor the survival of the microorganisms. Both technologies and the food matrix must aim to protect the microorganism's cells against external stress factors. In addition, once the food is consumed, the effect of digestion through the gastrointestinal system must be taken into account [69]. Foods that contain probiotic microorganisms with beneficial properties represent the largest segment of functional food on the market. For benefits to be obtained, foods containing probiotics must be consumed regularly and the food matrix must contain a minimum amount of viable probiotic microorganisms. The use of fruits and vegetables as vehicles for probiotic microorganisms represents a challenge. However, several factors can influence the viability of the probiotic microorganism. These factors can be inherent to the food matrix, such as fat and protein content, sugar composition, $\mathrm{pH}$, and presence of antimicrobial substances, in addition to those linked to the process (oxygen level, presence of preservatives, storage time, and temperature) [70]. In this regard, probiotic microorganisms must survive not only the shelf life of the food product but also the passage through the gastrointestinal tract (GIT) [35]. The low $\mathrm{pH}$ of the stomach combined with the presence of bile in the intestine can affect survival, which could directly influence the proliferation and colonization of probiotics in the intestinal tract [71].

Although the in vitro test has limitations to assess the viability of a probiotic strain in humans, it is very useful for selecting the strains that, when introduced into a food matrix, behave more satisfactorily [35] [71]. Table 3 shows some studies focused on the gastrointestinal viability of some strains with probiotic activity.

The main concern of the industry is ensuring the viability of probiotics is essential, due to the adverse conditions of food matrices, which can affect the viability and gastrointestinal resistance of these microorganisms. Therefore, the results found in several studies strengthen the processing and marketing of these products, ensuring the transmission of probiotics to consumers [71].

Table 3. Gastrointestinal viability tests of probiotic strains.

\begin{tabular}{cccc}
\hline \multicolumn{1}{c}{ Strain } & Food Matrix & Study & Reference \\
\hline Bifidobacterium animalis & Juçara juice & In vitro & {$[53]$} \\
Ligilactobacillus salivarius & Apple juice & In vitro & {$[70]$} \\
Lacticaseibacillus rhamnosus & Pineapple juice with juçara & In vitro & {$[71]$} \\
Lacticaseibacillus rhamnosus & Guava juice & In vitro & {$[72]$} \\
Lacticaseibacillus casei & & & \\
Lactobacillus acidophilus & Mao luang Juice & In vitro & {$[73]$} \\
Lacticaseibacillus rhamnosus & Apple juice & In vitro & {$[74]$} \\
Lactiplantibacillus plantarum & Apple juice & In vitro & {$[75]$} \\
\hline
\end{tabular}




\section{Effects of the Food Matrix on Cell Viability}

In dairy-based probiotic foods, the physical-chemical composition of the milk, which is rich in proteins and lipids (fats), acts as a protective matrix for probiotics and these factors help the survival of probiotics from adverse conditions of the stomach and small intestine. However, matrices of non-dairy foods are very different from those based on dairy products; they are more versatile and less understood [65].

The big challenge is the application of probiotic cultures in different beverages based on food matrices. Different probiotic species show different sensitivities concerning substrate acidity, dissolved oxygen, post-acidification in fermented beverages, metabolism products, temperatures, and conditions of the gastrointestinal tract [67].

To exercise their probiotic activity, the live microorganisms must be in an adequate quantity, resisting the adverse conditions of digestion and reaching the intestine in a sufficient dose to effectively develop and promote the benefits to the host. The viability and metabolic activity of the bacteria are important characteristics of the inclusion of probiotics in beverages. This occurs because the bacteria need to survive in the beverage during the expiration date and on the gastrointestinal digestion [67]. Therefore, the choice of the food matrix is an essential part to maintain the probiotic viability in the final product. Fruit juices and smoothies can be challenging matrices and their effects on probiotic viability are worth investigating since organic acids and phenolic compounds commonly present in fruits can exhibit microbiological properties. On the other hand, the content of the phenolic compounds can contribute to the survival of probiotic bacteria in food and even exert an effect similar to a prebiotic in the human intestine [53].

The formulation of beverages can favor their stability. Storage temperature is also a relevant factor in maintaining probiotic activity. There is a general recommendation that probiotic foods should preferably be stored between $4^{\circ} \mathrm{C}$ and $5^{\circ} \mathrm{C}[53]$.

Sugar supports the multiplication of probiotics, so, in theory, the use of sugar by the probiotic in juices will decrease the sugar content and increase the acidity of the juice [76]. In general, according to previous studies, the growth and viability of probiotic bacteria in fruit and vegetable beverages depends on the species and variety of bacteria used, the $\mathrm{pH}$, and the concentration of lactic and acetic acid in the final production [77]. The applicability of probiotics in food products generally depends on factors such as water activity, processing, and storage temperature, expiration date, oxygen content, $\mathrm{pH}$, mechanical stress, salt content, and content of other harmful or essential ingredients [78]. The non-dairy sources are fortified with acidulants that can increase the shelf life by creating an anaerobic environment that is ideal for probiotic cultures, which is achieved by eliminating the available oxygen. One more advantage is that these juices stay much less time in the stomach and, therefore, probiotic species spend much less 
time in the acidic environment of the stomach [65].

Strategies can be used to improve the viability of probiotic microorganisms, such as proper selection of acid and bile resistant strains, use of oxygen-impermeable containers, two-stage fermentation, microencapsulation, and incorporation of micronutrients such as peptides and amino acids [37].

Technological advances have made it possible to alter some structural characteristics of the matrices of fruits and vegetables, modifying components of these foods in a controlled manner, which can make them ideal substrates for probiotic strains [78].

The survival of the bacteria within the host and the preservation of dedicated properties remains a problem, even with the use of encapsulation. The optimization of the process and product design, cell viability and probiotic functionality, and strict fermentation quality control (culture medium or food matrix, $\mathrm{pH}$, temperature, carbon source composition, and fermentation time) and post-fermentation processing (spray drying, lyophilization, homogenization, mixing and high-pressure tablets, packaging, etc.). Sublethal stress during production can be useful to improve resistance to probiotics in foods and food additives can be avoided by encapsulation process [31].

\section{Consumer Study and Potential Market}

Sensory evaluation is a very important issue and has a direct association with product quality, processing characteristics, and consumer acceptability. Therefore, an appropriate selection of substrate composition and formations is necessary [77]. In addition to the above challenges, the sensory characteristics and general acceptance of non-dairy probiotic products also have some limitations. Thus, sensory evaluation of probiotic microorganisms in non-dairy products and consumer acceptance testing are of vital commercial importance [37].

It is important to consider the sensory acceptance by consumers during the development of non-dairy probiotic products, concerning appearance, aroma, texture, or flavor, to convey the direction for the production and ideal formulation of these products, always observing which are the expectations of consumers about these products. The attractive taste and the refreshing profile offered by fruit juices have stimulated a genuine interest in the industry for the development of fruit juices with the addition of probiotics [65]. Interactions between different probiotic strains and food substrates, where textures, flavors, aromas, and colors can be improved or aggravated by the production of different metabolic compounds, such as lactic acid and other metabolites during processing and storage, can influence the sensory properties of probiotic foods non-dairy. When preparing food with the addition of probiotics, the probiotic bacteria ferment the carbohydrates present in fruits, vegetables, cereals, and vegetables, releasing gases and alcohol. Some individuals report that the addition of probiotics to fruit juices can result in flavors described as "milky", "medicinal", "acidic", "salty", "bitter", "astringent", "artificial”, or "earthy". 
Some studies show that probiotics do not affect the general acceptance of fruit juices, this can happen depending on the type of fruit, the probiotic organism, the temperature at which they are stored, and the supplementation of prebiotics [37].

However, inadequate content of aromas (perfumery, dairy products) and flavors (sour, salty) have been reported when Lactobacillus plantarum was added to juices. A sensory impact study showed that consumers prefer the sensory characteristics of the conventional orange juice to their functional equivalent (juice containing probiotics), but if their information on health benefits is provided, preference increases over conventional orange juice [78].

The perception of unpleasant flavors in juices, resulting from the addition of probiotics that contribute to consumer dissatisfaction, can be overcome by adding $10 \%(\mathrm{v} / \mathrm{v})$ of tropical fruit juices [65].

The value of the global market for probiotics is around $\$ 15$ billion per year and is increasing by $7 \%$. Today, these probiotic products represent between $60 \%$ and $70 \%$ of the total functional food market, demonstrating their importance. The global probiotic food and beverage market was worth around 24.8 billion euros in 2011 and more than 31.1 billion euros in 2015 [37]. This value is expected to reach up to $\$ 69.3$ billion by 2023 , which also represents the driving force behind the functional beverages market. The estimate in 2019 was that the market for supplements containing probiotics would increase from $\$ 48$ billion to $\$ 62$ billion in 2022.

Non-dairy food products have gained popularity in the past decade. It is expected that the food products business reach approximately $\$ 26$ billion over the next five years. However, the manufacture of fermented probiotic foods at the commercial level faces many challenges, including the selection and identification of economical and abundant substrates, reducing operating expenses, and improving probiotic viability [44]. The willingness of the consumers to buy products incorporated with probiotics explains why they use functional beverages to improve their health [43].

The first non-dairy probiotic was produced by a Swedish company called Skane Dairy in 1994, since then many non-dairy probiotic drinks are already on the market. The basis of this product was oat flour fermented by Lactiplantibacillus plantarum. A similar product Good Belly (another company), prepared from oats and Lactiplantibacillus plantarum, was the first non-dairy probiotic launched on the US market in 2006 [37].

\section{Technological Challenges in the Food Industry with the Addition of Probiotics}

The selection of the appropriate probiotic strains in an appropriate dose and food matrix is the first requirement for the development of a food product with the addition of probiotics. Fruits, vegetables, and cereals represent a good matrix of probiotic bacteria with good nutraceutical components. However, some limitations can prevent the production of non-dairy probiotics at an industrial level, 
such as sensory characteristics, general acceptance, and, most importantly, the survival of probiotics over storage [79] [80]. To achieve these health benefits, the viability of probiotics through different conditions after consumption is crucial. The selected microorganisms must be able to tolerate bile and acid, colonization in the human intestine, good adhesion to people's epithelial cells; good growth characteristics, not being pathogenic and good impact on people's health [48].

The probiotic strains selected for use in the food industry must be stable during storage as chilled, frozen, or dried crops, and suitable for large-scale in industrial production with the ability to survive and maintain their functionality [10].

The greatest difficulty in the production of dairy beverages with probiotic properties is the preservation of the product's physical stability. The optimization of the process of these beverages needs more care, including a selection of concentration and type of stabilizer and optimization of pretreatment conditions, such as homogenization regimes. Storage at room temperature, which is common in many types of non-dairy products, can create a major challenge for probiotic viability [37].

The proper scientific validation of claims for functional food products remains a critical issue for food science. Especially issues of safety, biocompatibility, and health claim of functional milk-based and/or non-dairy beverages are often recorded or evaluated with inadequate/insufficient methodologies. An interdisciplinary approach must be followed to create a solid scientific base for the functionality of the beverages in question [78].

New products need to take advantage of emerging technologies based on nanotechnology, high-pressure homogenization during processing, and methods that better preserve viability during storage, to increase the manufacture and consumption of products with the addition of probiotics [49].

Non-dairy foods must be developed with the addition of probiotics, allowing the consumption of these beneficial microorganisms by people who do not like dairy products or who are intolerant or allergic to milk components. There are two main challenges with a probiotic product: the maintenance of the physical-chemist and sensory characteristics equivalent to conventional products without probiotics and the maintenance of the viability of the microorganism during the lifespan of these products with the guarantee of the passage of the probiotic through the gastrointestinal tract, reaching in a sufficient quantity in the intestine to exert its probiotic activity [81]. Despite the challenges, the future of non-dairy products with probiotics is promising [37].

\section{Conclusions}

Since fruits and vegetables can be used as raw materials for a probiotic fermentation, this takes into account the biochemical and physicochemical composition of these raw materials. In addition to the content of health-promoting phytochemicals in fruits and vegetables, they also offer several advantages such as adding value to products and extending the shelf life of processed foods. 
The development of new technologies that are more economically appropriate, and of matrices with technological potential for the industry is extremely important for the supply of non-dairy probiotic foods according to the demand they have. Although there is great potential for the use of fruit juices as probiotic products, there are few reports on their preparation and production and this needs to be intensified.

Innovative technologies for the preparation of probiotic food products to improve their nutritional value need to be an urgent priority area.

\section{Acknowledgements}

This work was carried out with the support of the Coordenação de Aperfeiçoamento de Pessoal de Nível Superior-Brazil (CAPES) - Financing Code 001, University of Minho, Rio de Janeiro State Research Foundation (FAPERJ, E-26.202.749/2018) and National Council for Scientific and Technological Development (CNPq, 311936/2018-0).

\section{Conflicts of Interest}

The authors declare no conflict of interest.

\section{References}

[1] Yeung, A.W.K., Mocan, A. and Atanasov, A.G. (2018) Let Food Be Thy Medicine and Medicine Be Thy Food: A Bibliometric Analysis of the Most Cited Papers Focusing on Nutraceuticals and Functional Foods. Food Chemistry, 269, 455-465. https://doi.org/10.1016/j.foodchem.2018.06.139

[2] Xie, J., Liang, J. and Chen, N. (2019) Autophagy-Associated Signal Pathways of Functional Foods for Chronic Diseases. Food Science and Human Wellness, 8, 25-33. https://doi.org/10.1016/j.fshw.2019.03.002

[3] Cavalcante, R.S. (2016) Efeitos das tecnologias emergentes não térmicas empregadas no processamento de suco prebiótico de maçã. Fortaleza, Chapter 1.

[4] Iwatani, S. and Yamamoto, N. (2019) Functional Food Products in Japan: A Review. Food Science and Human Wellness, 8, 96-101. https://doi.org/10.1016/j.fshw.2019.03.011

[5] Ye, Q., Georges, N. and Selomulya, C. (2018) Microencapsulation of Active Ingredients in Functional Foods: From Research Stage to Commercial Food Products. Trends in Food Science and Technology, 79, 167-179.

https://doi.org/10.1016/j.tifs.2018.05.025

[6] Silva, A.C.C., Silva, N.A., Pereira, M.C.S. and Vassimon, H.S. (2016) Alimentos contendo ingredientes funcionais em sua formulação: Revisão de artigos publicados em revistas brasileiras. Revista Conexão ciêNcia, 11, 133-144.

https://doi.org/10.24862/cco.v11i2.429

[7] Tripathi, M.K. and Giri, S.K. (2014) Probiotic Functional Foods: Survival of Probiotics during Processing and Storage. Journal of Functional Foods, 9, 225-241. https://doi.org/10.1016/j.jff.2014.04.030

[8] Champagne, C.P., Cruz, A.G. and Daga, M. (2018) Strategies to Improve the Functionality of Probiotics in Supplements and Foods. Current Opinion in Food Science, 22, 160-166. https://doi.org/10.1016/j.cofs.2018.04.008 
[9] Galanakis, C. (2019) Survival of Probiotics in Functional Foods during Shelf Life. In: Dinkci, N., Akdeniz, V. and Akalin, A.S., Eds., Food Quality and Shelf Life, Academic Press, Elsevier, 201-233. https://doi.org/10.1016/B978-0-12-817190-5.00006-9

[10] Rodrigues, V.C.C., Silva, L.G.S., Simabuco, F.M., Venema, K. and Antunes, A.E.C. (2019) Survival, Metabolic Status and Cellular Morphology of Probiotics in Dairy Products and Dietary Supplement after Simulated Digestion. Journal of Functional Foods, 55, 126-134. https://doi.org/10.1016/j.jff.2019.01.046

[11] Espitia, P.J.P., Batista, R.A., Azeredo, H.M.C. and Otoni, C.G. (2016) Probiotics and Their Potential Applications in Active Edible Films and Coatings. Food Research International, 90, 42-52. https://doi.org/10.1016/j.foodres.2016.10.026

[12] Simone, C. (2019) The Unregulated Probiotic Market. Clinical Gastroenterology and Hepatology, 17, 809-817. https://doi.org/10.1016/j.cgh.2018.01.018

[13] Pimentel, T.C., Madrona, G.S., Garcia, S. and Prudencio, S.H. (2015) Probiotic Viability, Physicochemical Characteristics and Acceptability during Refrigerated Storage of Clarified Apple Juice Supplemented with Lactobacillus paracasei ssp. Paracasei and Oligofructose in Different Package Type. LWT-Food Science and Technology, 63, 415-422. https://doi.org/10.1016/j.lwt.2015.03.009

[14] Hill, C., Guarner, F., Reid, G., Gibson, G.R., Merenstein, D.J., Pot, B., Morelli, L., Canani, R.B., Flint, H.J., Salminen, S., Calder, P.C. and Sanders, M.E. (2014) The International Scientific Association for Probiotics and Prebiotics Consensus Statement on the Scope and Appropriate Use of the Term Probiotic. Nature Reviews Gastroenterology \& Hepatology, 11, 506-514. https://doi.org/10.1038/nrgastro.2014.66

[15] World Gastroenterology Organization (2017) Global Guidelines Probiotics and Prebiotics.

[16] Lesnick-Dreher, S.M., Schreirer, J. and Stibitz, S. (2015) Development of Phage Lysin LysA2 for Use in Improved Purity Assays for Live Biotherapeutic Products. Viruses, 7, 6675-6688. https://doi.org/10.3390/v7122965

[17] Butel, M.J. (2014) Probiotics, Gut Microbiota and Health. Médecine et maladies infectieuses, 44, 1-8. https://doi.org/10.1016/j.medmal.2013.10.002

[18] Brasil. Ministério da Saúde. Agência Nacional de Vigilância Sanitária (2002) Resolução $\mathrm{n}^{\circ}$ 2, de 07 de janeiro de 2002. Aprova o Regulamento Técnico de Substâncias Bioativas e Probióticos Isolados com Alegação de Propriedades Funcional e ou de Saúde. Diário Oficial [da República Federativa do Brasil], Brasília, DF, 7 de janeiro de.

[19] Valero-Cases, E., Cerdá-Bernard, D., Pastor, J.J. and Frutos, M.J. (2020) Non-Dairy Fermented Beverages as Potential Carriers to Ensure Probiotics, Prebiotics, and Bioactive Compounds Arrival to the Gut and Their Health Benefits. Nutrients, 12, 666. https://doi.org/10.3390/nu12061666

[20] Brasil. Ministério da Saúde. Agência Nacional de Vigilância Sanitária (2008) Informações Técnicas. Alimentos com Alegações de Propriedades Funcionais e ou de Saúde, Novos Alimentos/Ingredientes, Substâncias Bioativas e Probióticos. Diário Oficial [da República Federativa do Brasil], Brasília, DF, julho de.

[21] Rai, A.K., Pandey, A. and Sahoo, D. (2019) Biotechnological Potential of Yeasts in Functional Food Industry. Trends in Food Science and Technology, 83, 129-137. https://doi.org/10.1016/j.tifs.2018.11.016

[22] Silva, B.V., Barreira, J.C.M. and Oliveira, M.B.P.P. (2016) Natural Phytochemicals and Probiotics as Bioactive Ingredients for Functional Foods: Extraction, Biochemistry and Protected-Delivery Technologies. Trends in Food Science and Technology, 50, 144-158. https://doi.org/10.1016/j.tifs.2015.12.007 
[23] Fazilah, N.F., Ariff, A.B., Khayat, M.E., Rios-Solis, L. and Halim, M. (2018) Influence of Probiotics, Prebiotics, Synbiotics and Bioactive Phytochemicals on the Formulation of Functional Yogurt. Journal of Functional Foods, 48, 387-399. https://doi.org/10.1016/j.jff.2018.07.039

[24] Kothari, D., Patel, S. and Kim, S.K. (2019) Probiotic Supplements Might Not Be Universally-Effective and Safe: A Review. Biomedicine \& Pharmacotherapy, 111, 537-547. https://doi.org/10.1016/j.biopha.2018.12.104

[25] Kerry, R.G., Patra, J.K., Gouda, S., Park, Y., Shin, H.S. and Das, G. (2018) Benefaction of Probiotics for Human Health: A Review. Journal of Food and Drug Analysis, 26, 927-939. https://doi.org/10.1016/j.jfda.2018.01.002

[26] Pot, B., Salvetti, E., Mattarelli, P. and Felis, G.E. (2019) The Potential Impact of the Lactobacillus Name Change: The Results of an Expert Meeting Organised by the Lactic Acid Bacteria Industrial Platform (LABIP). Trends in Food Science \& Technology, 94, 105-113. https://doi.org/10.1016/j.tifs.2019.07.006

[27] Garrity, G.M. (2016) A New Genomics-Driven Taxonomy of Bacteria and Archaea: Are We There Yet? Journal of Clinical Microbiology, 54, 1956-1963.

https://doi.org/10.1128/JCM.00200-16

[28] Lugli, G.A., Milani, C., Duranti, S., Mancabelli, L., Mangifesta, M., Turroni, F., Viappiani, A., Sinderen, D. and Ventura, M. (2018) Tracking the Taxonomy of the Genus Bifidobacterium Based on a Phylogenomic Approach. Applied and Environmental Microbiology, 84, e02249-17. https://doi.org/10.1128/AEM.02249-17

[29] Mattarelli, P., Holzapfel, W., Franz, C.M.A.P., Endo, A., Feliz, G.E., Hammes, W., Pot, B., Dicks, L. and Dellaglio, F. (2014) Recommended Minimal Standards for Description of New Taxa of the Genera Bifidobacterium, Lactobacillus and Related Genera. International Journal of Systematic and Evolutionary Microbiology, 64, 1434 1451. https://doi.org/10.1099/ijs.0.060046-0

[30] Zheng, J., Wittouck, S., Salvetti, E., Franz, C.M.A.P., Harris, H.M.B., Mattarelli, P., O'Toole, P.W., Pot, B., Vandamme, P., Walter, J., Watanabe, K., Wuyts, S., Felis, G.E., Ganzle, M.G. and Lebeer, S. (2020) A Taxonomic Note on the Genus Lactobacillus. Description of 23 Novel Genera, Emended Description of the Genus Lactobacillus Beijerinck 1901, and Union of Lactobacillaceae and Leuconostocaceae. International Journal of Systematic and Evolutionary Microbiology, 70, 2782-2858. https://doi.org/10.1099/ijsem.0.004107

[31] Foligné, B., Daniel, C. and Pot, B. (2013) Probiotics from Research to Market: The Possibilities, Risks and Challenges. Current Opinion in Microbiology, 16, 284-292. https://doi.org/10.1016/j.mib.2013.06.008

[32] Pimentel, T.C., Costa, W.K.A., Barão, C.E., Rosset, M. and Magnani, M. (2020) Vegan Probiotic Products: A Modern Tendency or the Newest Challenge in Functional Foods. Food Research International, 2020, Article ID: 110033.

https://doi.org/10.1016/j.foodres.2020.110033

[33] Guan, Q., Xiong, T. and Xie, M. (2020) Influence of Probiotic Fermented Fruit and Vegetables on Human Health and the Related Industrial Development Trend. Engineering, 7, 212-218. https://doi.org/10.1016/j.eng.2020.03.018

[34] Reid, G. (2016) Probiotics: Definition, Scope and Mechanisms of Action. Best Practice \& Research: Clinical Gastroenterology, 30, 17-25. https://doi.org/10.1016/j.bpg.2015.12.001

[35] Soares, M.B., Martineza, R.C.R., Pereira, E.P.R., Balthazarb, C.F., Cruz, A.G., Ranadheerad, S. and Sant'anna, A.S. (2019) The Resistance of Bacillus, Bifidobacterium, and Lactobacillus Strains with Claimed Probiotic Properties in Different Food Ma- 
trices Exposed to Simulated Gastrointestinal Tract Conditions. Food Research International, 125, Article ID: 108542.

https://doi.org/10.1016/j.foodres.2019.108542

[36] Agah, S., Akbari, A., Heshmati, J., Sepidarkshi, M., Morvaridzadeh, M., Adibi, P., Mazidi, M., Farsi, F., Ofori-Asenso, R., Talley, N.J. and Feinle-Bisset, C. (2020) Systematic Review with Meta-Analysis: Effects of Probiotic Supplementationon Symptoms in Functional Dyspepsia. Journal of Functional Foods, 68, Article ID: 103902. https://doi.org/10.1016/j.jff.2020.103902

[37] Aspri, M., Papademas, P. and Tsaltas, D. (2020) Review on Non-Dairy Probiotics and Their Use in Non-Dairy Based Products. Fermentation, 6, 1-20. https://doi.org/10.3390/fermentation6010030

[38] Niu, H.L. and Xiao, J.Y. (2020) The Efficacy and Safety of Probiotics in Patients with Irritable Bowel Syndrome: Evidence Based on 35 Randomized Controlled Trials. International Journal of Surgery, 75, 116-127.

https://doi.org/10.1016/j.ijsu.2020.01.142

[39] Sen, S. and Mansell, T.J. (2020) Yeasts as Probiotics: Mechanisms, Outcomes, and Future Potential. Fungal Genetics and Biology, 137, Article ID: 103333.

https://doi.org/10.1016/j.fgb.2020.103333

[40] Rivera-Flores, R., Morán-Villota, S., Cervantes-Barragán, L., López-Macias, C. and Uribe, M. (2020) Manipulation of Microbiota with Probiotics as an Alternative for Treatment of Hepatic Encephalopathy. Nutrition, 73, Article ID: 110693. https://doi.org/10.1016/j.nut.2019.110693

[41] Zang, C., Yu, Z., Zao, J., Zhang, H., Zhai, Q. and Chen, Q. (2019) Colonization and Probiotic Function of Bifidobacterium longum. Journal of Functional Foods, 53, 157-165. https://doi.org/10.1016/j.jff.2018.12.022

[42] Cheng, D., Song, J., Xie, M. and Song, D. (2019) The Bidirectional Relationship between Host Physiology and Microbiota and Health Benefits of Probiotics: A Review. Trends in Food Science \& Technology, 91, 426-435. https://doi.org/10.1016/j.tifs.2019.07.044

[43] Di Cagno, R., Filannino, P., Cantatore, V., Polo, A., Celano, G., Martinovic, A., Cavoski, I. and Gobbetti (2020) Design of Potential Probiotic Yeast Starters Tailored for Making a Cornelian Cherry (Cornus mas L.) Functional Beverage. International Journal of Food Microbiology, 323, Article ID: 108591.

https://doi.org/10.1016/j.ijfoodmicro.2020.108591

[44] Behera, S.S. and Panda, S.K. (2020) Ethnic and Industrial Probiotic Foods and Beverages: Efficacy and Acceptance. Current Opinion in Food Science, 33, 29-36. https://doi.org/10.1016/j.cofs.2020.01.006

[45] Al-Qysi, L., Mohammad, M., Al-Iedani, A. and Abukhader, M.M. (2020) Investigating the Characteristics of Probiotics Marketed in the Middle East and Pharmacists' Perception of Use in Muscat, Oman. Pharma Nutrition, 13, Article ID: 1002020. https://doi.org/10.1016/j.phanu.2020.100202

[46] Alasmar, R., Varadharajan, K., Shanmugakonar, M. and Al-Naemi, H. (2019) Gut Microbiota and Health: Understanding the Role of Diet. Food and Nutrition Sciences, 10, 1344-1373. https://doi.org/10.4236/fns.2019.1011097

[47] Bambace, M.F., Alvarez, M.V. and Moreira, M.R. (2019) Novel Functional Blueberries: Fructo-Oligosaccharides and Probiotic Lactobacilli Incorporated into Alginate Edible Coatings. Food Research International, 122, 653-660. https://doi.org/10.1016/j.foodres.2019.01.040

[48] Panghal, A., Janghu, S., Virkar, K., Gat, Y., Kumar, V. and Chhikara, N. (2018) Po- 
tential Non-Dairy Probiotic Products-A Healthy Approach. Food Bioscience, 21, 80-89. https://doi.org/10.1016/j.fbio.2017.12.003

[49] Tesfaye, W., Suarez-Lepe, J.A., Loira, I., Palomero, F. and Morata, A. (2019) Dairy and Nondairy-Based Beverages as a Vehicle for Probiotics, Prebiotics, and Symbiotics: Alternatives to Health versus Disease Binomial Approach through Food. Milk Based Beverages, 9, 473-520. https://doi.org/10.1016/B978-0-12-815504-2.00014-1

[50] Bampi, G.B., Backes, G.T., Cansian, R.L., Matos, F.E., Ansolin, I.M.A., Poleto, B.C., Corezzolla, L.R. and Favaro-Trindade, C.S. (2016) Spray Chilling Microencapsulation of Lactobacillus acidophilus and Bifidobacterium animalis subsp. lactis and Its Use in the Preparation of Savory Probiotic Cereal Bars. Food and Bioprocess Technology, 9, 1-7. https://doi.org/10.1007/s11947-016-1724-Z

[51] Chavan, M., Gat, Y., Harmalkar, M. and Waghmare, R. (2018) Development of Non-Dairy Fermented Probiotic Drink Based on Germinatedand Ungerminated Cereals and Legume. LWT-Food Science and Technology, 9, 339-344.

https://doi.org/10.1016/j.lwt.2018.01.070

[52] Dias, C.O., Almeida, J.S.O., Pinto, S.S., Santana, F.C.O., Verruck, S., Müller, C.M.O., Prudêncio, E.S. and Amboni, R.D.M.C. (2018) Development and Physico-Chemical Characterization of Microencapsulated Bifidobacteria in Passion Fruit Juice: A Functional Non-Dairy Product for Probiotic Delivery. Food Bioscience, 24, 26-36. https://doi.org/10.1016/j.fbio.2018.05.006

[53] Zheng, X., Yu, Y., Xiao, G., Xu, Y., Wu, J., Tang, D. and Zhang, Y. (2014) Comparing Product Stability of Probiotic Beverages Using Litchi Juice Treated by High Hydrostatic Pressure and Heat as Substrates. Innovative Food Science and Emerging Technologies, 23, 61-67. https://doi.org/10.1016/j.ifset.2014.01.013

[54] Ribeiro, A.P.O., Gomes, F.S., Santos, K.M.O., Matta, V.M., Sá, D.G.C.F., Santiago, M.C.P.A., Conte, C., Costa, S.D.O., Ribeiro, L.O., Godoy, R.L.O. and Walter, E.H.M. (2020) Development of a Probiotic Non-Fermented Blend Beverage with Juçara Fruit: Effect of the Matrix on Probiotic Viability and Survival to the Gastrointestinal Tract. LWT-Food Science and Technology, 118, Article ID: 108756. https://doi.org/10.1016/j.lwt.2019.108756

[55] Li, Z., Teng, J., Lyu, Y., Hu, X., Zhao, Y. and Wang, M. (2019) Enhanced Antioxidant Activity for Apple Juice Fermented with Lactobacillus plantarum ATCC14917. Molecular, 14, 51. https://doi.org/10.3390/molecules24010051

[56] Xu, X., Bao, Y., Wu, B., Lao, F., Hu, X. and Wu, J. (2019) Chemical Analysis and Flavor Properties of Blended Orange, Carrot, Apple and Chinese Jujube Juice Fermented by Selenium-Enriched Probiotics. Food Chemistry, 289, 250-258. https://doi.org/10.1016/j.foodchem.2019.03.068

[57] Valero-Cases, E., Roy, N.C., Frutos, M.J. and Anderson, R.C. (2017) Influence of the Fruit Juice Carriers on the Ability of Lactobacillus plantarum DSM20205 to Improve in Vitro Intestinal Barrier Integrity and Its Probiotic Properties. Journal of Agricultural and Food Chemistry, 65, 5632-5638. https://doi.org/10.1021/acs.jafc.7b01551

[58] Kaprasob, R., Kerdchoechuen, O., Laohakunjit, N. and Somboonpanyakul, P.B. (2018) Vitamins and Prebiotic Fructooligosaccharides of Cashew Apple Fermented with Probiotic Strains Lactobacillus spp., Leuconostoc mesenteroides and Bifidobacterium longum. Process Biochemistry, 70, 9-19. https://doi.org/10.1016/j.procbio.2018.04.009

[59] Ricci, A., Cirlini, M., Maoloni, A., Del Rio, D., Calani, L., Bernini, V., Galaverna, G, 
Neviani, E. and Lazzi, C. (2019) Use of Dairy and Plant-Derived Lactobacilli as Starters for Cherry Juice Fermentation. Nutrients, 11, 1-14.

https://doi.org/10.3390/nu11020213

[60] Mantzourani, I., Nouska, C., Terpou, A., Alexopoulos, A., Bezirtzoglou, E., Panayiotidis, M.I., Galanis, A. and Plessas, S. (2018) Production of a Novel Functional Fruit Beverage Consisting of Cornelian Cherry Juice and Probiotic Bacteria. Antioxidants, 7, 2-10. https://doi.org/10.3390/antiox7110163

[61] Costa, M.G.M., Fontenelles, T.V., Jesus, A.L.T. and Rodrigues, S. (2013) Sonicated Pineapple Juice as Substrate for $L$. casei Cultivation for Probiotic Beverage Development: Process Optimisation and Product Stability. Food Chemistry, 139, 261-266. https://doi.org/10.1016/j.foodchem.2013.01.059

[62] Pereira, A.L.F., Maciel, T.C. and Rodrigues, S. (2011) Probiotic Beverage from Cashew Apple Juice Fermented with Lactobacillus casei. Food Research International, 44, 1276-1283. https://doi.org/10.1016/j.foodres.2010.11.035

[63] Mousavi, Z.E., Mousavi, S.M., Razavi, S.H., Eman-Djomeh, Z. and Kiani, H. (2011) Fermentation of Pomegranate Juice by Probiotic Lactic Acid Bactéria. World Journal of Microbiology and Biotechnology, 27, 123-128. https://doi.org/10.1007/s11274-010-0436-1

[64] Nagpal, R., Kumar, A. and Kumar, M. (2020) Fortification and Fermentation of Fruit Juices with Probiotic Lactobacilli. Annals of Microbiology, 62, 1573-1578. https://doi.org/10.1007/s13213-011-0412-5

[65] Sheehan, V.M., Ross, P. and Fitzgerald, G.F. (2007) Assessing the Acid Tolerance and the Technological Robustness of Probiotic Cultures for Fortification in Fruit Juices. Innovative Food Science and Emerging Technologies, 8, 279-284.

https://doi.org/10.1016/j.ifset.2007.01.007

[66] Kumar, B.V., Vijayendra, S.V.N. and Reddy, O.V.S. (2015) Trends in Dairy and Non-Dairy Probiotic Products-A Review. Journal of Food Science and Technology, 52, 6112-6124. https://doi.org/10.1007/s13197-015-1795-2

[67] Terpou, A., Papadaki, A., Lappa, I.K., Kachrimanidou, V., Bosnea, L.A. and Kopsahelis, N. (2019) Probiotics in Food Systems: Significance and Emerging Strategies towards Improved Viability and Delivery of Enhanced Beneficial Value. Nutrients, 11, 1591. https://doi.org/10.3390/nu11071591

[68] Pires, E.A., Ferreira, M.A., Vieira, R.B., Barbosa, C.A. and Santos, F.L. (2015) Perfil dos documentos de patentes referentes a tecnologias e produtos probióticos, prebióticos e simbióticos na América Latina. Cadernos de Prospecção, 8, 142-149. https://doi.org/10.9771/S.CPROSP.2015.001.016

[69] Souza, A.L.C., Souza, R.R., Lobato, L.P., Cavalcante, R.C.M. and Silva, G.F. (2018) Estudo prospectivo de produtos probióticos não lácteos de patentes depositados no Brasil. Revista Gestão, Inovação e Tecnologias, 8, 4533-4539. https://doi.org/10.7198/geintec.v8i3.1206

[70] Meneses, T.S.C. and Santos, J.A.B. (2016) Análise do cenário de patentes de produtos probióticos via bases tecnológicas INPI, ESPACENET e WIPO. 7 th International Symposium on Technological Innovation, Vol. 3, 155-165. https://doi.org/10.7198/S2318-3403201600030020

[71] Ester, B., Noeliab, B., Laurab, C.J., Francesca, P., Cristina, B., Rosalbac, L. and Marco, D.R. (2019) Probiotic Survival and in Vitro Digestion of L. salivarius spp. salivarius Encapsulated by High Homogenization Pressures and Incorporated into a Fruit Matrix. LWT-Food Science and Technology, 111, 883-888.

https://doi.org/10.1016/j.lwt.2019.05.088 
[72] Campos, R.C.A.B., Martins, E.M.F.M., Pires, B.A., Peluzio, M.G.C., Campos, A.N.R., Ramos, A.M., Leite, B.R.C., Martins, A.D.O., Silva, R.R. and Martins, M.L. (2019) In Vitro and in Vivo Resistance of Lactobacillus rhamnosus GG Carried by a Mixed Pineapple (Ananas comosus L. Merril) and Jussara (Euterpe edulis Martius) Juice to the Gastrointestinal Tract. Food Research International, 116, 1247-1257. https://doi.org/10.1016/j.foodres.2018.10.012

[73] Andrade, R., Santos, E., Azoubel, P. and Ribeiro, E. (2019) Increased Survival of Lactobacillus rhamnosus ATCC 7469 in Guava Juices with Simulated Gastrointestinal Conditions during Refrigerated Storage. Food Bioscience, 32, Article ID: 100470. https://doi.org/10.1016/j.fbio.2019.100470

[74] Chaikham, P., Kemsawasd, V. and Seesuriyachan, P. (2017) Spray Drying Probiotics along with Maoluang Juice plus Tiliacora triandra Gum for Exposure to the in Vitro Gastrointestinal Environments. LWT-Food Science and Technology, 78, 31-40. https://doi.org/10.1016/j.lwt.2016.12.013

[75] Gandomi, H., Abbaszadeh, S., Misaghi, A., Bokaie, S. and Noori, N. (2016) Effect of Chitosan-Alginate Encapsulation with Inulin on Survival of Lactobacillus rhamnosus GG during Apple Juice Storage and under Simulated Gastrointestinal Conditions. LWT-Food Science and Technology, 69, 365-371. https://doi.org/10.1016/j.lwt.2016.01.064

[76] Roberts, D., Reyesb, B., Bonillab, F.., Dzandub, B, Liub, C., Chouljenkob, A. and Sathivelb, S. (2018) Viability of Lactobacillus plantarum NCIMB 8826 in Fermented Apple Juice under Simulated Gastric and Intestinal Conditions. LWT_Food Science and Technology, 97, 144-150. https://doi.org/10.1016/j.lwt.2018.06.036

[77] White, J. and Hekmat, S. (2018) Development of Probiotic Fruit Juices Using Lactobacillus rhamnosus GR-1 Fortified with Short Chain and Long Chain Inulin Fiber. Fermentation, 4, 27. https://doi.org/10.3390/fermentation4020027

[78] Shori, A.B. (2016) Influence of Food Matrix on the Viability of Probiotic Bacteria: A Review Based on Dairy and Non-Dairy Beverages. Food Bioscience, 13, 1-8. https://doi.org/10.1016/j.fbio.2015.11.001

[79] Vasudha, S. and Mishra, H.N. (2013) Non Dairy Probiotic Beverages. International Food Research Journal, 20, 7-15.

[80] Turkmen, N., Akal, C. and Ozer, B. (2019) Probiotic Dairy-Based Beverages: A Review. The Journal of Functional Foods, 53, 62-75.

https://doi.org/10.1016/j.jff.2018.12.004

[81] Reale, A., Renzo, T. and Coppola, R. (2019) Factors Affecting Viability of Selected Probiotics during Cheese-Making of Pasta Filata Dairy Products Obtained by Direct-to-Vat Inoculation System. LWT-Food Science and Technology, 116, Article ID: 108476. https://doi.org/10.1016/j.lwt.2019.108476 